\title{
P3 mAb: an immunogenic anti-NeuGcGM3 antibody with unusual immunoregulatory properties
}

\author{
Darel Martínez ${ }^{1}$, Nely Rodríguez ${ }^{1}$, Tania Griñán ${ }^{1}$, Teresa Rondón ${ }^{1}$, Ana María Vázquez ${ }^{2}$, Rolando Pérez $^{3}$ and \\ Ana María Hernández ${ }^{1}$ *
}

${ }^{1}$ Tumor Immunology Direction, Center of Molecular Immunology, Havana, Cuba

2 Innovation Management Direction, Center of Molecular Immunology, Havana, Cuba

${ }_{3}^{3}$ Molecular Immunology Institute, Center of Molecular Immunology, Havana, Cuba

\section{Edited by:}

Tim L. Manser, Thomas Jefferson University, USA

Reviewed by:

Ziaur Aka Zia S. Rahman, Thomas

Jefferson University/Jefferson

Medical College, USA

Martin Bachmann, Cytos

Biotechnology, Switzerland

*Correspondence:

Ana María Hernández, Tumor Immunology Direction, Center of

Molecular Immunology, 216 Street

and 15th Avenue, P.O. Box. 16040,

Havana 11600, Cuba.

e-mail:anita@cim.sld.cu
P3 is a murine $\operatorname{lgM} m A b$ that recognize $N$-glycosylated gangliosides, sulfatides, and antigens expressed in melanoma, breast, and lung human tumors. This antibody has the ability to trigger an IgG antibody response in the syngeneic BALB/c model, even when it is administered in the absence of adjuvant or carrier protein. The mechanism by which the P3 mAb, a self-immunoglobulin, induce this immune response in the absence of co-stimulatory or classical danger signals is still unknown. In the present paper we show that the high immunogenicity of P3 mAb depends not only on CD4 but also on $\mathrm{CD}^{+} \mathrm{T}$ cells, since the depletion of $\mathrm{CD}^{+}$or $\mathrm{CD} 4^{+} \mathrm{T}$ cells led to the loss of P3 mAb immunogenicity in the syngeneic model. Furthermore, the immunization with P3 mAb enhanced the recovery of the $\mathrm{CD}^{+} \mathrm{T}$ cell population in mice treated with an anti-CD8a antibody. Additionally, the immunization with P3 mAb restored the capacity of immunosuppressed mice to reject allogeneic tumors, a mechanism mediated by the action of $\mathrm{CD}^{+} \mathrm{T}$ cells. Finally, in mice with cyclophosphamide induced lymphopenia, the administration of P3 mAb accelerated the recovery of both $\mathrm{CD} 4^{+}$and $\mathrm{CD} 8^{+} \mathrm{T}$ cells. These results show new possibilities for $\mathrm{B}$ and $\mathrm{CD} 8^{+} \mathrm{T}$ cells interactions during the immune response elicited by a self-protein. Furthermore they point to $\mathrm{P} 3 \mathrm{mAb}$ as a potential interesting candidate for the treatment of immunosuppressed patients.

Keywords: CD8T cells, immunogenicity, immunoregulation, monoclonal antibody

\section{INTRODUCTION}

P3 mAb is an Ab1 antibody that recognizes NeuGc-containing gangliosides, sulfated glycolipids, and antigens present in different human tumors including those from the lung, breast, and melanoma (Vazquez et al., 1995). VH P3 is of germ line origin and belongs to the Q52 (VH II) gene family, previously observed in autoantibodies against gangliosides and frequently used by $\mathrm{CD}^{+}$ B lymphocytes (Perez et al., 2001). This antibody is capable of triggering a strong anti-idiotypic (Ab2) response in the syngeneic model, even in the absence of adjuvant or carrier protein (Vazquez et al., 1998), which is a phenomenon rarely observed (Baskin et al., 1990; Maruyama et al., 2002).

Some authors have suggested that the IgM isotype confers certain advantages for the development of anti-idiotypic responses (Baskin et al., 1990; Reitan and Hannestad, 1995, 2002), but it has been shown that this is not a general property of the IgM anti-ganglioside antibodies (Vazquez et al., 1998; Reitan and Hannestad, 2001), which suggest that the variables regions of the immunogenic antibodies could contain antigenic determinants that could be responsible for their unusual immunogenicity. In fact, the immunogenicity of $\mathrm{P} 3 \mathrm{mAb}$ idiotype has also been demonstrated in the absence of any constant domain (Rodriguez et al., 2007). Some authors have shown that the presence of somatic hypermutations is an important factor in the immunogenicity of autologous immunoglobulins (Zaghouani et al., 1992; Eyerman and Wysocki, 1994; Cao et al., 1995; Eyerman et al., 1996; Wysocki et al., 1998; Zhang et al., 2001). However, P3 mAb variable region is coded by germ line genes (Perez et al., 2001), so the presence of somatic hypermutations is not the cause of its high immunogenicity (Rodriguez et al., 2007). In fact, Reitan and Hannestad (2001) analyzed the syngeneic immunogenicity, in the absence of adjuvant, of the idiotypes of $73 \mathrm{mAb}$ of IgM isotype. These researchers reported that the four antibodies that generated high levels of anti-idiotypic IgG antibodies, were coded by germ line genes.

Based on structural modeling and immunogenetic analysis, several P3 mAb mutants were obtained by substituting the basic residues R31, R98, and R100a, of the H-CDRs of the variable regions of P3. Immunization experiments with these mutants proved that these basic residues play a critical role in both its binding specificity and high immunogenicity (Lopez-Requena et al., 2007a,b).

The fact that P3 mAb induces anti-idiotypic antibodies of IgG isotype suggests the participation of $\mathrm{T}$ cells in the generation of this response. This is very interesting since P3 is a selfimmunoglobulin, presented to the immune system in the absence of the classical co-stimulatory signals (Caux et al., 1994; Tseng et al., 2001). Previous data already published by our group showed that lymph node cells from BALB/c mice immunized with $\mathrm{P} 3 \mathrm{mAb}$ proliferated in vitro, in a dose-dependent manner, not only in the 
presence of $\mathrm{P} 3 \mathrm{mAb}$ but also in the presence of 1E10, one of its anti-idiotypic Ab2 mAb. This result suggests that $\mathrm{P} 3 \mathrm{mAb}$ is able to activate B-T cell idiotypic networks (Perez et al., 2002).

All these results prompted us to evaluate the immunogenicity of P3 mAb in different mouse strains, and to study the importance of different $\mathrm{T}$ cell populations in the induction of this unusual anti-idiotypic response, which could contribute to understand the mechanism underlying this unusual immunogenicity. Although for many years it was believed that the Th1/Th2 paradigm only applied to $\mathrm{CD} 4^{+} \mathrm{T}$ cells, several studies have shown that $\mathrm{CD}^{+} \mathrm{T}$ cells can also provide B cell help (Jacobsen et al., 1993; Cronin et al., 1995; Hermann et al., 1995). Thus in the present work we wanted to study the contribution of both $\mathrm{CD} 4{ }^{+}$ and also $\mathrm{CD}^{+} \mathrm{T}$ cells in the induction of an anti-idiotypic response.

\section{RESULTS}

\section{HUMORAL RESPONSE TO P3 mAb}

Three important factors to characterize the immune response against a given antigen are the kinetic of the response, the influence of the immunization route, and the importance of the use of an adjuvant to achieve the response. To assess the significance of these factors for P3 mAb immunogenicity, first, BALB/c mice were immunized intraperitoneally, intramuscularly, or subcutaneously with four doses of this antibody in phosphate buffered saline (PBS). We detected an antibody response against P3 mAb in most immunized animals regardless the route of immunization used. However the level of the antibody response was significantly higher in animals immunized subcutaneously (Figure 1).

Next we studied if the presence of an adjuvant changes P3 immunogenicity. For this purpose we evaluated the IgG antibody

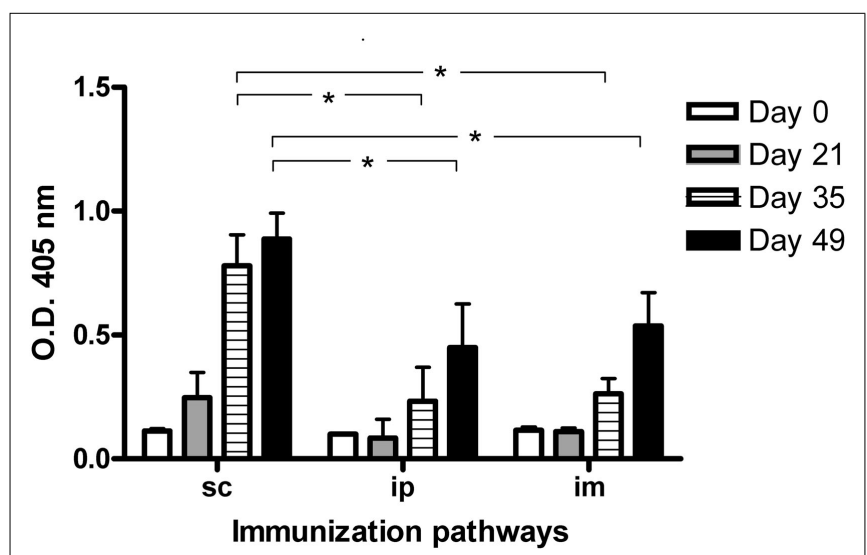

FIGURE 1 | lgG antibodies response in BALB/c mice immunized with P3 $\mathbf{m A b}$ using different routes of immunization. $B A L B / c$ mice were immunized with four doses of P3 mAb in PBS using different routes of immunization: subcutaneously (s.c.), intraperitoneally (i.p.), or intramuscular (i.m.). The blood samples were obtained before the immunization and 7 days after the second, third, and fourth doses (days 21, 35, and 49 of the immunization protocol). Sera were diluted 1:100 and the response against purified P3 mAb was assessed by ELISA, reactivity was determined using alkaline phosphatase-conjugated goat anti-mouse IgG (Fc $\gamma$-specific). Values are expressed as means $\pm \mathrm{SD}(n=5)$. ${ }^{*} p<0.05$, Mann-Whitney $U$ test, one-tailed. response induced in $\mathrm{BALB} / \mathrm{c}$ mice immunized subcutaneously with P3 only in PBS or emulsified in Freund's adjuvant. Furthermore we compare the response induced in mice that received four doses of $\mathrm{P} 3 \mathrm{mAb}$ at 2 weeks intervals or a single dose of the antibody. As is shown in Figure 2, the mice immunized with four doses of $\mathrm{P} 3 \mathrm{mAb}$ generated an antibody response of the IgG isotype independently on the use of Freund's adjuvant. This response was specific for P3 mAb idiotype since did not cross react with an irrelevant IgM used as isotype control (Figure A1 in Appendix). The response was detected from the second dose for the animals immunized with adjuvant and from the third for those immunized only with P3/PBS. Furthermore, mice immunized with a single dose of $\mathrm{P} 3 \mathrm{mAb}$ in the presence of Freund's adjuvant, elicited an IgG antibody response detectable at day 21 after immunization, moment equivalent to the second dose of the mice that received four doses. Although these mice received only one dose of $\mathrm{P} 3 \mathrm{mAb}$, the anti-P3 antibody response continued increasing in time and 49 days after immunization reached levels that did not show significant differences with those obtained in the animals immunized with four doses. We could not detect any antibody response of the IgG isotype in the animals that received only one dose of P3 mAb in PBS (Figure 2).

Since P3 mAb has the rare ability to generate humoral immune response in the syngeneic BALB/c model, we wanted to establish whether it was equally immunogenic in a different mouse strain, like C57BL/6. The Figure 3 showed that, in contrast with the results obtained in syngeneic $\mathrm{BALB} / \mathrm{c}$ mice (Figure $3 \mathrm{~A}$ ), in the allogeneic inbred mice strain $\mathrm{C} 57 \mathrm{BL} / 6$, after four doses of $\mathrm{P} 3 \mathrm{mAb}$ immunization we could not detected any significant IgG antibody response at the dilution used (Figure 3B). However in the outbred NMRI mice strain we could detect a significant IgG response after four doses in all the mice tested (Figure 3C).



FIGURE 2 | Kinetic of IgG antibodies response in BALB/c mice. Mice were immunized with one (1d) or four (4d) doses of P3 mAb in PBS or emulsified in Freund's adjuvant (FA). The blood samples were obtained before the immunization and on days 7, 21, 35, and 49 of the immunization protocol. Sera were diluted 1:100 and the reactivity against purified P3 mAb was assessed by ELISA. Binding was determined using alkaline phosphatase-conjugated goat anti-mouse IgG (Fc $\gamma$-specific). Values are expressed as means $\pm \operatorname{SD}(n=5)$. 

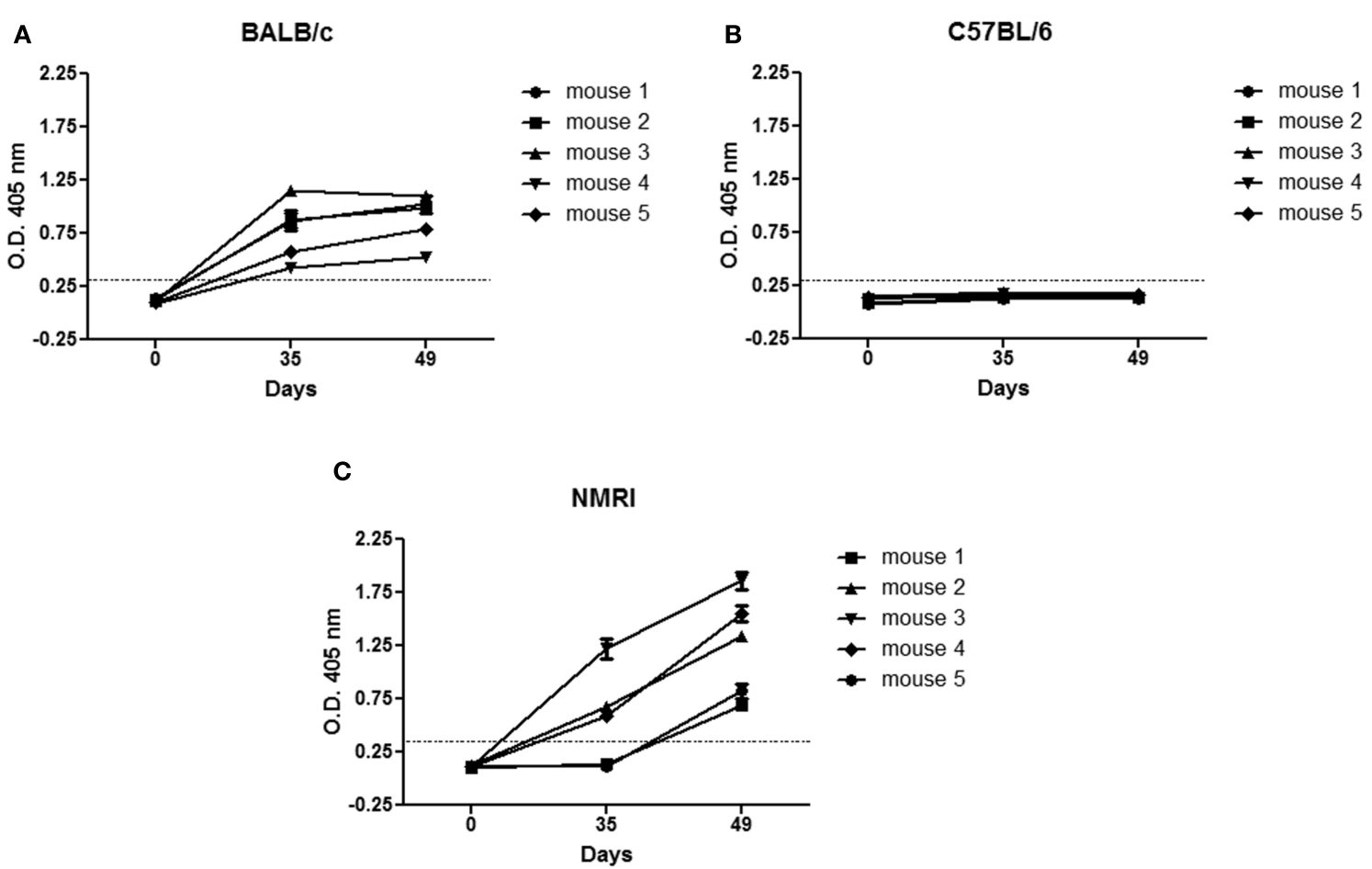

FIGURE 3 | Immunogenicity of P3 mAb in different mice strains. BALB/C (A), C57BL/6 (B), or NMRI (C) mice were immunized subcutaneously with four doses of P3 mAb in PBS every 2 weeks. The sera samples were taken before the immunization period (day 0 ) and after the third (day 35) and fourth (day 49) dose. The reactivity was determined by ELISA in P3 mAb coated plates using alkaline phosphatase-conjugated goat anti-mouse lgG (FC $\gamma$-specific). For each mouse, is graphed the means \pm SD of each of the values obtained in triplicate.

\section{IMPORTANCE OF T CELLS IN THE ANTIBODY RESPONSE AGAINST P3 mAb}

Since the immunization with P3 mAb induce antibodies of IgG isotype and depends on the mouse strain, next we evaluated the participation of $\mathrm{T}$ cells in the induction of this antibody response. For this purpose $\mathrm{CD}^{+}{ }^{+}$or $\mathrm{CD}^{+}{ }^{+} \mathrm{T}$ cells were depleted with antiCD4 or anti-CD8a antibodies at different moments during the immunization protocol and the antibody response after the fourth dose was tested by ELISA. As is shown in Figure 4, a significant decrease in the antibody response was detected in the sera of the animals treated before the first dose of $\mathrm{P} 3 \mathrm{mAb}$ (group 2), with the anti-CD4 (Figure 4A) but also in those treated with the anti-CD8a antibody (Figure 4B). There were not significant differences in the response of the groups treated before the second and the third dose with any of the depleting antibodies (group 3 and 4; Figure 4C).

\section{IN VIVO RESTORATION OF CD8+ ${ }^{+}$LYMPHOCYTES BY P3 mAb}

Due to the involvement of $\mathrm{CD}^{+} \mathrm{T}$ cells in the induction of the antibody response against $\mathrm{P} 3 \mathrm{mAb}$, we studied if the immunization with this antibody increase the percentage of $\mathrm{CD}^{+} \mathrm{T}$ cells in the inguinal lymph node of BALB/c mice treated with the anti-CD8a antibody. The results showed that the percentage of $\mathrm{CD}^{+} \mathrm{T}$ cells in mice immunized with $\mathrm{P} 3 \mathrm{mAb}$ was significantly higher than the one detected in mice treated with the control antibody or PBS (Figure 5A). In the C57BL/6 strain, where P3 is not immunogenic, we could not detect any difference in the $\mathrm{CD}^{+} \mathrm{T}$ cells percentage between the mice immunize with $\mathrm{P} 3$ or with the controls (Figure 5B).

\section{EFFECT OF P3 mAb IN F3II MEDIATED ENGRAFTMENT OF ALLOGENEIC B16-F10 TUMOR IN BALB/c MICE}

Next we tested the ability of this antibody to stimulate an immune system affected for the presence of a tumor. We used a model of tumor induced immunosuppression where BALB/c mice were inoculated with the syngeneic F3II tumor cells, which make them susceptible to the engraftment of the allogeneic B16-F10 tumor cells. One week before the syngeneic tumor inoculation the mice received the first of four, biweekly, doses of $\mathrm{P} 3 \mathrm{mAb}$, and the allogeneic tumor development on immunized and not treated mice was compared. As shown in Figure 6, the immunization with P3 mAb increased the percentage of animals able to reject the allogeneic tumor. Fifty percent of non-immunized mice developed allogeneic B16-F10 in comparison with only $19 \%$ of P3 mAb immunized mice. P3 mAb did not have any effect on the kinetics of engraftment or the tumor size in the mice that did not reject the allogeneic tumor (data not shown).

\section{CAPACITY OF P3 mAb TO RECOVERY T CELL POPULATIONS IN LYMPHOPENIC MICE}

To further evaluate the therapeutic potential of this antibody, we tested the ability of $\mathrm{P} 3 \mathrm{mAb}$ to stimulate in vivo the recovery of different lymphocyte populations in a model of induced lymphopenia (Zuluaga et al., 2006) that resemble the state of immune 

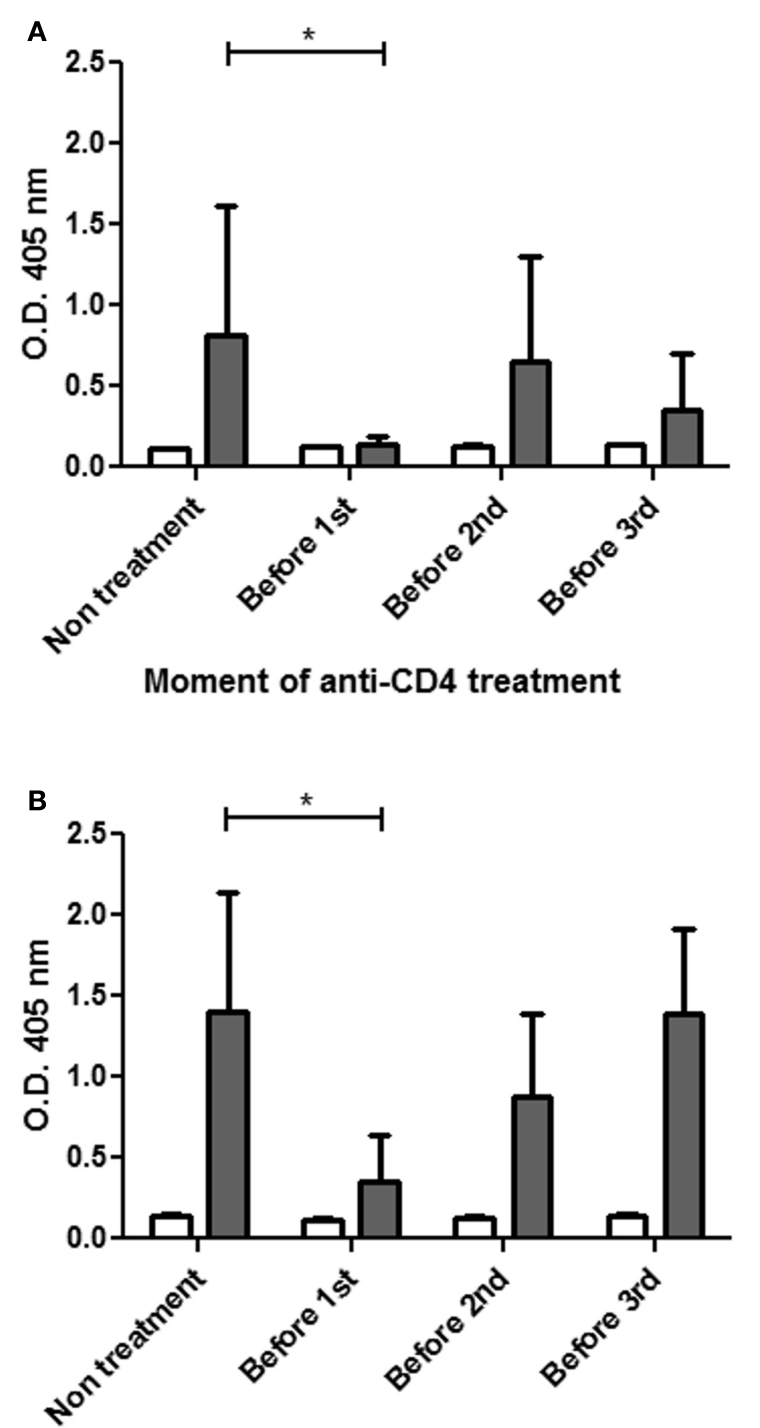

Moment of anti-CD8a treatment

FIGURE 4 | Differences in the IgG antibodies response against P3 mAb in $B A L B / c$ mice treated in different moments of the protocol with CD4a or CD8a depleting antibodies. BALB/c mice were immunized with four doses of P3 mAb in PBS and were treatment with an anti-CD4a (A) or anti-CD8a (B) depleting antibody only once before one of the dose of P3 (except the fourth). Sera were diluted 1:100 and the reactivity against purified P3 mAb was

\section{$\square$ Preimmune 4th dose}

C

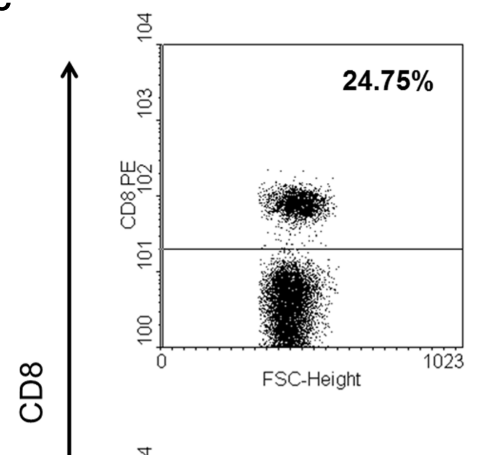

Preimmune 4th dose



assessed by ELISA. Binding was determined using alkaline phosphatase-conjugated goat anti-mouse lgG (Fc $\gamma$-specific). (C) A representative effect on $\mathrm{CD}^{+}$cell populations of the treatment with one dose of anti-CD8a depleting antibody, upper figure showed control mouse and lower figure showed treated mouse. Values are expressed as means $\pm \operatorname{SD}(n=5) .{ }^{*} p<0.05$, Mann-Whitney $U$ test, one-tailed.

suppressed patients. BALB/c mice treated with cyclophosphamide were inoculated with $\mathrm{P} 3$ or an irrelevant $\mathrm{mAb}$, and the recovery of the lymphocyte populations was measured by flow cytometry. As is shown in Figure 7, mice that received P3 $\mathrm{mAb}$ and not the ones treated with the control $\mathrm{mAb}$, showed a significant increase in the percentage of $\mathrm{CD}^{+}{ }^{+}$and $\mathrm{CD} 8^{+} \mathrm{T}$ populations after the cyclophosphamide treatment. Mice that received only cyclophosphamide or cyclophosphamide plus control mAb showed $18-21 \%$ of $\mathrm{CD}^{+} \mathrm{T}$ cells and $14-19 \%$ of $\mathrm{CD}^{+} \mathrm{T}$ cells regarding the normal cell number in not immune-compromised mice. However $\mathrm{P} 3$ treated mice showed an increase up to $46 \%$ for $\mathrm{CD}^{+}{ }^{+} \mathrm{T}$ and $50 \%$ for $\mathrm{CD} 8^{+} \mathrm{T}$ cells. There were no significant differences in the B cells percentages between the different groups (Figure 7). This result is not observed in C57BL/6 mice where we could not detect differences between the controls and the mice treated with P3 mAb (data not shown).

\section{DISCUSSION}

The high immunogenicity of autologous immunoglobulins is not a phenomenon frequently observed (Ismaili et al., 1995), and in particular the generation of a response against anti-ganglioside $\mathrm{mAb}$ in the syngeneic model has been reported in very few studies, 


\section{A}

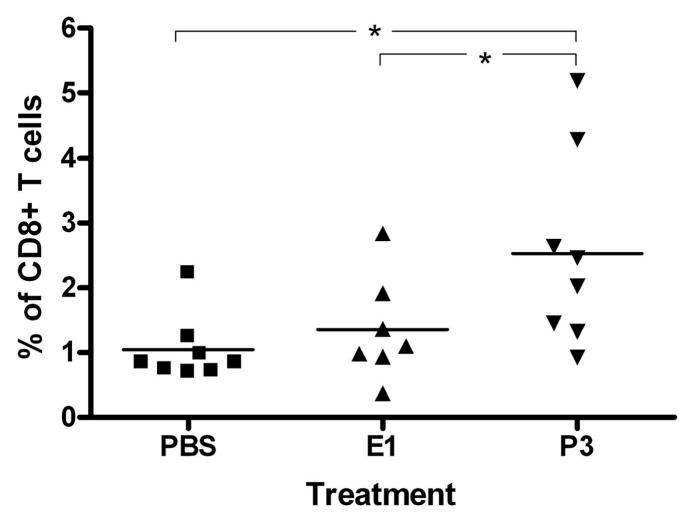

FIGURE 5 | Regeneration of the population of $\mathrm{CD8}^{+} \mathrm{T}$ cells by the action of the P3 mAb. BALB/c (A) or C57BL/6 (B) mice inoculated with P3 mAb, control mAb (E1), or PBS were intraperitoneally treated with anti-CD8a depleting antibody. The expression of the CD8a molecule in
B

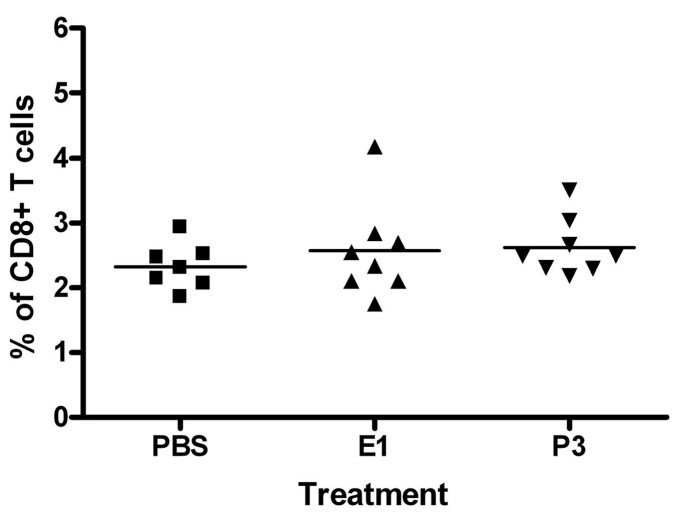

lymph node cells was determined by flow cytometry for which the cells were incubated with a fluorescein isothiocyanate-conjugated anti-mouse CD8a. Values represent means $\pm \operatorname{SD}(n=8) .{ }^{*} p<0.05$, Dunnett $t$-test, one-tailed.

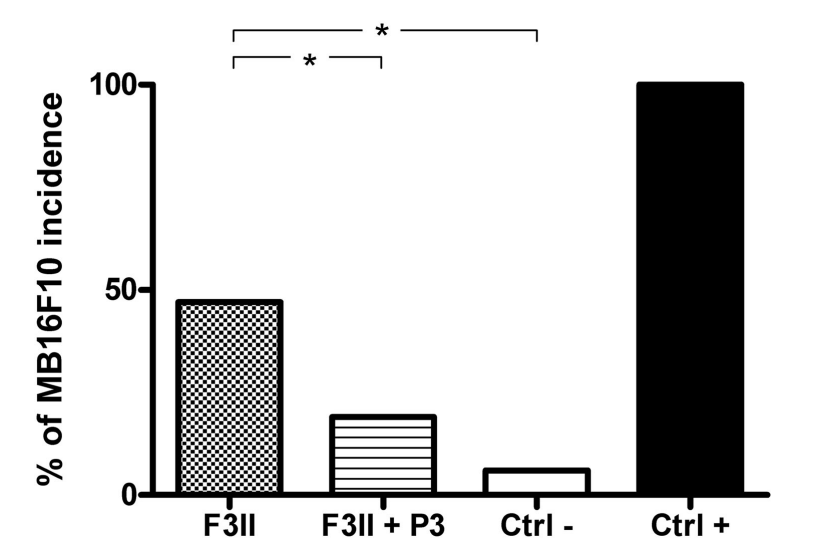

FIGURE 6 | Immunization with P3 mAb retrieves the ability of allogeneic MB16F10 tumor rejection in BALB/c mice immunosuppressed by syngeneic F3II tumor. Mice inoculated with F3II tumor and treated or not with P3 mAb were challenged with MB16F10 tumor. The bars indicate the percentage of mice developing tumors. The values represent the mean of two different experiments. Ctrl-: BALB/c mice that were not inoculated with F3II tumor, Ctrl+: C57BL/6 mice, in which the tumor MB16F10 are syngeneic. ${ }^{*} p<0.05$, Pearson's chi-square $\left(\chi^{2}\right)$ test, one-tailed.

always using adjuvant or carrier protein (Chapman and Houghton, 1991; Saleh et al., 1993). However, P3 mAb is a germline antiNeuGcGM3 IgM that is highly immunogenic, in the absence of adjuvant or carrier protein, in the syngeneic model. Furthermore, the immunization with this antibody induces not only B cell, but also T cell idiotypic networks (Perez et al., 2002). The first aim of our work was to further study the high immunogenicity of this antibody and to evaluate the role of $\mathrm{T}$ cells in this phenomenon.

There have been reports about variations in the induction of humoral responses against a given antigen depending on the route of inoculation used (Fynan et al., 1993; Raz et al., 1994). Although we detected an antibody response against P3 mAb when it was inoculated by subcutaneous, intramuscular, or intraperitoneal route, this response was significantly higher by the subcutaneous immunization. This could be related with a slower speed of antigen release or due to differences in the specific APC populations in the site of immunization.

The generation of an antibody response against a proteic antigen, such as antibodies, is generally favored by the number of doses and by the presence of adjuvant (Cox and Coulter, 1997; Stills, 2005). When P3 mAb was inoculated only in PBS, at least three doses were necessary to induce the immune response. However when it was inoculated in the presence of Freund's adjuvant, only one dose was enough to induce an IgG response that had not significance differences, regarding the magnitude or the kinetic, with the one achieved with four doses. This result confirms the ability of this antibody to be autoimmunogenic in the syngeneic model and suggest that the slow release of small amounts of the antibody to the circulation, induced by the depot effect of the adjuvant, favor the induction of a strong immune response. On the other hand this could be a result of the capacity of this antibody to activate $\mathrm{T}$ cell idiotypic networks (Perez et al., 2002; Rodriguez et al., 2007).

Evidence that suggest the participation of $\mathrm{T}$ cells in the anti$\mathrm{P} 3$ response is the fact that despite the high immunogenicity in $\mathrm{BALB} / \mathrm{c}$ mice, there was no antibody response against $\mathrm{P} 3 \mathrm{mAb}$ after the immunization of C57BL/6 mice with four doses of the $\mathrm{mAb}$ in PBS. These differences in the humoral response against P3 mAb between in different mice strains could be because $\mathrm{T}$ cells recognize $\mathrm{P} 3 \mathrm{mAb}$ epitopes presented by $\mathrm{BALB} / \mathrm{c}$ strain specific MHC haplotypes, as has been described for other antigens (Misharin et al., 2009). On the other hand, P3 mAb also induced an anti-idiotypic response in NMRI mice, an outbred strain, showing that its immunogenic properties are not exclusive for BALB/c mice haplotype.

An interesting result of our experiments was that not only the depletion of $\mathrm{CD} 4^{+} \mathrm{T}$ cells, but also of $\mathrm{CD} 8^{+} \mathrm{T}$ cells, deeply affected the induction of the anti-idiotypic response. The depletion of the $\mathrm{CD}^{+}{ }^{+}$or $\mathrm{CD}^{+} \mathrm{T}$ cells before the first dose of $\mathrm{P} 3$ abrogated the 



FIGURE 7 | Recovery of the populations of $\mathrm{CD}^{+}$and $\mathrm{CD8}^{+} \mathrm{T}$ cells by immunization with $\mathrm{P3}$ mAb in BALB/c mice treated with

cyclophosphamide. Mice were inoculated with two doses of cyclophosphamide and then received an intravenous dose of the P3 mAb or control mAb (E1). It was determined the amount of cells in inguinal lymph



nodes (A), and subpopulations of $\mathrm{CD}^{+} \mathrm{T}(\mathbf{B}), \mathrm{CD} 8^{+} \mathrm{T}(\mathbf{C})$, and $\mathrm{B}$ cells (D) by flow cytometry. It is considered as $100 \%$ the number of cells from animals not treated with cyclophosphamide (PBS group). Values represent means $\pm \mathrm{SD}(n=5)$ in a representative experiment of three. ${ }^{*} p<0.05$, Dunnett $t$-test, one-tailed. antibody response, suggesting an important role for these cells at the first stages of the anti-idiotypic response. Although historically $\mathrm{CD}^{+} \mathrm{T}$ cells have been regarded as cytotoxic cells, several studies have shown their capacity to activate the immune responses, providing help for DC (Nakamura et al., 2007), NK (Shanker et al., 2007), and B cells (Cronin et al., 1995). It has become clear the existence of $\mathrm{CD}^{+} \mathrm{T}$ cell subsets analogous to the Th1 and Th2 CD4 counterparts in mice (Croft et al., 1994; Cronin et al., 1995; Sad et al., 1995) and humans (Salgame et al., 1991; Maggi et al., 1994; Birkhofer et al., 1996).

On the other hand, the antibody response in BALB/c mice deficient of $\mathrm{CD}^{+} \mathrm{T}$ cells, immunized with $\mathrm{P} 3 \mathrm{mAb}$ emulsified in Freund's adjuvant, does not vary significantly with respect to the response in the mice with a normal $\mathrm{CD}^{+} \mathrm{T}$ cell population (data not shown). The action of the adjuvant to enhance the immune response, by activating dendritic cells (Salem et al., 2006; Agger et al., 2008), might counteract the effect caused by the deficiency of $\mathrm{CD}^{+} \mathrm{T}$ cells. These results suggest that in the induction of an anti-P3 antibody response, $\mathrm{CD}^{+} \mathrm{T}$ cells could play a role equivalent to that of an adjuvant, probably as activators of the antigen presenting cells or directly activating the anti-idiotypic antibody secreting B cell (Lu et al., 2002). Another possible role of $\mathrm{CD}^{+} \mathrm{T}$ cells could be to eliminate or suppress some regulatory cell populations (Hahn et al., 2005), that could inhibit the induction of the antibody response against $\mathrm{P} 3 \mathrm{mAb}$. Although the interaction between Id $+\mathrm{B}$ cell and $\mathrm{CD} 4^{+} \mathrm{T}$ cells have been previously published (Weiss and Bogen, 1991; Bogen and Weiss, 1993; Munthe et al., 1999; Jacobsen et al., 2010), to our knowledge, this is the first report that involves $\mathrm{CD} 8^{+} \mathrm{T}$ cells in the induction of an anti-idiotypic response in vivo. This result opens new possibilities for the understanding of the regulation and activation of B cell-T cell idiotypic networks.

Due to the importance of $\mathrm{CD}^{+} \mathrm{T}$ cells for the humoral response against $\mathrm{P} 3$, and knowing that $\mathrm{P} 3 \mathrm{mAb}$ is able to induce $\mathrm{T}$ cells proliferation in vitro (Perez et al., 2002), we studied if this antibody could have some impact on the $\mathrm{CD} 8^{+} \mathrm{T}$ cell population in vivo. First we depleted the $\mathrm{CD} 8^{+}$populations in mice that were treated with $\mathrm{P} 3 \mathrm{mAb}$ or an irrelevant control antibody. In fact, 
the percent of $\mathrm{CD}^{+} \mathrm{T}$ cell recovery in $\mathrm{CD}^{+}$cells depleted mice previously immunized with P3 was significantly higher than the one detected in the animals treated with the control antibody. This result demonstrated that $\mathrm{P} 3 \mathrm{mAb}$ has the ability to help the recovery of the $\mathrm{CD}^{+} \mathrm{T}$ population in vivo. This could be a consequence of a proliferative effect over the remnant or new emerging $\mathrm{CD} 8^{+}$ $\mathrm{T}$ cells or due to the induction of a greater resistance to depletion by the cytotoxic antibody. Since the anti-CD8a antibody used cause complement dependent cell death (Cobbold et al., 1984), the induction of $\mathrm{CD}^{+} \mathrm{T}$ cell proliferation due to immunization would be the most suitable explanation.

In order to evaluate the functionality of the expanded $\mathrm{T}$ cells and the capacity of $\mathrm{P} 3 \mathrm{mAb}$ to reactivate an immunosuppressed immune system, we used an in vivo model. In this model BALB/c mice become susceptible to an allogeneic tumor, which would be rejected in immunocompetent mice, due to the immunosuppression induced by the inoculation of a syngeneic tumor. In our experiment, $50 \%$ of the BALB/c mice inoculated with the syngeneic breast tumor F3II showed B16-F10 allogeneic tumor growth, in contrast with only $19 \%$ on P3 treated mice. This result confirms that $\mathrm{P} 3 \mathrm{mAb}$ is able to recover functional $\mathrm{T}$ cells in situations of immunosuppression (Sauer et al., 2008).

Next we evaluated the capacity of $\mathrm{P} 3 \mathrm{mAb}$ to induce the recovery of $\mathrm{T}$ cell populations in a clinically relevant scenario, like the immunosuppression induced by cytotoxic drugs during cancer treatments. We could confirm that in mice immunosuppressed due to cyclophosphamide treatment, which affect both $\mathrm{T}$ and $\mathrm{B}$ cell populations (Zuluaga et al., 2006), the treatment with a single dose of $\mathrm{P} 3 \mathrm{mAb}$ also induced a significant increase in the recovery of $\mathrm{CD}^{+}$and $\mathrm{CD}^{+}$T. The same experiment performed in C57BL/6 mice did not show significant differences between the P3 mAb immunized and non-immunized mice (data not shown). This result confirms the ability of $\mathrm{P} 3 \mathrm{mAb}$ to induce T lymphocytes proliferation in $\mathrm{BALB} / \mathrm{c}$ mice.

The results in this work confirm the high immunogenicity of $\mathrm{P} 3 \mathrm{mAb}$ and proved the participation of $\mathrm{CD}^{+} \mathrm{T}$ cells during the induction phase of the immune response. Moreover, we showed that the immunization with $\mathrm{P} 3 \mathrm{mAb}$ reconstitutes in vivo T cell populations and improve immunosuppressed states in lymphopenic BALB/c mice. A fast reconstitution of $\mathrm{T}$ cell dependent immunity is a critical issue for patients treated with lymphodepleting regimens, which can produce higher susceptibility to infections, reduced response to vaccines and easier tumor relapse (Nordoy et al., 2001; Parkman et al., 2006; Aoki et al., 2012).

Some molecules with immunorestorative properties are being evaluated, which include IL-7, IL-2, and IL-15. IL-7 has shown a potent immunorestorative and vaccine adjuvant effects in preclinical studies. Several clinical trials with IL-7 are ongoing in settings of acquired immunodeficiency, chronic viral infection, and cancer, showing so far to be well tolerated and to induce immunorestoration, preferential of naïve T cells (Mackall et al., 2011). IL-2 has been used to boost effector immune responses in patients with cancers and infectious diseases and it is registered for the treatment of renal-cell carcinoma. However, the response to the treatment is achieved in less than $10 \%$ of the patients, probably because this cytokine stimulates regulatory $\mathrm{T}$ cells, which could suppress antitumor responses (Lemoine et al., 2009).
IL-15 is a potent proinflammatory cytokine, with antitumor effects in several preclinical mouse tumor models. However, administration of IL-15 alone was not optimal because it also activated immune system negative regulatory checkpoints that might affect the immune response (Yu et al., 2010).

In this article we show the first evidences that $\mathrm{P} 3 \mathrm{mAb}$ could improve immune restoration, especially for T cells. To our knowledge, this is the first report of an immunogenic antibody with this capacity. The negative impact of lymphopenia for cancer patients and the fact that in this moment there is not a product that has totally prove its effectiveness in the clinic; make it worthy to further study this important property of $\mathrm{P} 3 \mathrm{mAb}$. Furthermore, $\mathrm{P} 3$ has an especial characteristic that differentiates it from the rest of the molecules evaluated as immune-stimulators: P3 it is an antibody and it would be possible the active induction of P3-like antibodies sharing this property by anti-idiotypic immunization. In fact, $1 \mathrm{E} 10 \mathrm{mAb}, \mathrm{P} 3 \mathrm{mAb}$ anti-idiotype has been used in several clinical trials in lung, melanoma, and breast cancer patients, showing that is able to induce a specific "P3-like" anti-NeuGcGm3 response (Alfonso et al., 2002; Diaz et al., 2003; Hernandez et al., 2008).

Experiments to further study the phenotypes and functions of the induced $\mathrm{T}$ cell populations in immune compromise mice as well as to further understand the role of $\mathrm{CD}^{+} \mathrm{T}$ cells in the activation of immune networks are ongoing.

\section{MATERIALS AND METHODS ANIMALS}

Female BALB/c, C57BL/6, and NMRI mice, 6-8 weeks old, were purchased from the Center for Laboratory Animal Production (CENPALAB, Havana, Cuba). Animals were housed and bred in a barrier maintained room according to the guidelines stipulated by the Animal Subject Committee Reviews Board at the Center of Molecular Immunology (CIM). Animal studies were performed with approval from CIM's Institutional Animal Care and Use Committee.

\section{mAbs}

P3 mAb (IgM, $k$ ), recognizes NeuGc-containing gangliosides and sulfated glycolipids (Vazquez et al., 1995). P3 mAb was purified from ascitic fluid by gel filtration chromatography using a Sephacryl S-300 high-resolution column (Pharmacia) equilibrated with PBS containing $0.5 \mathrm{M} \mathrm{NaCl}$. E1 mAb (IgM, k, antiGM2), was used as isotype control. Anti-CD8a and anti-CD4a antibodies (IgG2b, k) were purified from supernatant of YTS 169.4.2.1 and YTS 191.1.1.2, respectively (Cobbold et al., 1984).

\section{CELLS}

Murine breast cancer F3II cells and melanoma B16-F10 cells were grown in RPMI-1640 medium (Gibco), supplemented with $10 \%$ fetal calf serum (FCS), $10 \mathrm{U} / \mathrm{mL}$ penicillin, and $10 \mathrm{mg} / \mathrm{mL}$ streptomycin. Tumor cells were counted and the viability was greater than $90 \%$, as assayed by trypan blue exclusion test.

\section{IMMUNIZATION PROTOCOLS Induction of antibody response against $P 3 \mathbf{m A b}$}

To evaluate the relevance of the immunization route for $\mathrm{P} 3$ $\mathrm{mAb}$ immunogenicity, BALB/c mice were immunized with four 
biweekly dose of $50 \mu \mathrm{g}$ of P3 mAb in PBS subcutaneous (s.c.), intramuscular (i.m.), or intraperitoneally (i.p.). To evaluate the importance of the dose number and the presence of adjuvant, $\mathrm{BALB} / \mathrm{c}$ mice were immunized with one or four dose of $50 \mu \mathrm{g}$ of P3 mAb, at 2 weeks intervals, subcutaneously, in the presence or absence of Freund's adjuvant. C57BL/6 and NMRI mice were immunized with four dose of $50 \mu \mathrm{g}$ of purified P3 mAb in PBS, at 2 weeks intervals, subcutaneously. Serum samples were taken before the first and 7 days after each immunization.

\section{Antibody response induction against $\mathrm{P3} \mathrm{mAb}$ in $\mathrm{CDB}^{+} \mathrm{T}$ cells depleted mice}

To determine the moment at which $\mathrm{CD} 8^{+}$and $\mathrm{CD} 4^{+} \mathrm{T}$ cells participate in the induction of the anti- $\mathrm{P} 3 \mathrm{mAb}$ response, three groups of $\mathrm{BALB} / \mathrm{c}$ mice were immunized four times at 2 weeks intervals, subcutaneously, with $50 \mu \mathrm{g}$ of $\mathrm{P} 3 \mathrm{mAb}$ and were inoculated with $1 \mathrm{mg}$ of anti-CD8a or anti-CD4 antibody intraperitoneally once before the first, the second or the third dose of $\mathrm{P} 3 \mathrm{mAb}$ immunization, respectively. $\mathrm{P} 3 \mathrm{mAb}$ immunized mice without anti-CD8a or anti-CD4 antibody treatment were used as control. Serum samples were taken before the first and 7 days after the fourth immunization.

\section{P3 $\mathbf{m A b}$ induction of in vivo stimulation of $C D 8^{+} T$ cells}

$\mathrm{BALB} / \mathrm{c}$ and $\mathrm{C} 57 \mathrm{BL} / 6$ mice were immunized subcutaneously with $50 \mu \mathrm{g}$ of $\mathrm{P} 3$ or $\mathrm{E} 1 \mathrm{mAbs}$ four times at 2 weeks interval. Three days after last immunization mice were inoculated with $1 \mathrm{mg}$ of anti-CD8a antibody intraperitoneally followed by two daily doses of $50 \mu \mathrm{g}$ of P3 or E1 mAbs, intravenously. Finally, $24 \mathrm{~h}$ after mice were sacrificed and their inguinal lymph nodes were extracted to analyze the number of $\mathrm{CD}^{+} \mathrm{T}$ cell by flow cytometry.

\section{Allogeneic tumor rejection protocol}

$\mathrm{BALB} / \mathrm{c}$ mice were immunized four times at 2 weeks intervals, subcutaneously, with $50 \mu \mathrm{g}$ of P3 mAb. Eight days after the first P3 $\mathrm{mAb}$ immunization mice were inoculated with breast tumor cell line F3II $\left(2 \times 10^{5}\right.$ cells per mouse, subcutaneously $)$ and 21 days later with the allogeneic melanoma cell line B16-F10 $\left(5 \times 10^{5}\right.$ cells per mouse, subcutaneously). C57BL/6 and BALB/c mice inoculated only with melanoma B16-F10 cells were used as positive and negative control, respectively. The tumor size measurement started 7 days after melanoma inoculation, twice a week. For ethical reasons, animals were sacrificed when the general condition of the animals was affected.

\section{REFERENCES}

Agger, E. M., Cassidy, J. P., Brady, J., Korsholm, K. S., Vingsbo-Lundberg, C., and Andersen, P. (2008). Adjuvant modulation of the cytokine balance in Mycobacterium tuberculosis subunit vaccines; immunity, pathology and protection. Immunology 124, 175-185.

Alfonso, M., Diaz, A., Hernandez, A. M., Perez, A., Rodriguez, E., Bitton, R., Perez, R., and Vazquez, A. M. (2002).

\section{P3 mAb induction of lymphocytes population recovery after cyclophosphamide treatment}

BALB/c mice were treated with two doses of cyclophosphamide $(200 \mathrm{mg} / \mathrm{kg})$ at 4 days interval. Two days later mice were inoculated with $50 \mu \mathrm{g}$ of $\mathrm{P} 3$ or E1 mAbs, intravenously. After $48 \mathrm{~h}$ mice were sacrificed and their inguinal lymph nodes were extracted, cell number was counted used Neubauer's chamber. Percent of each lymphocytes population $\left(\mathrm{CD} 4^{+} \mathrm{T}, \mathrm{CD} 8^{+} \mathrm{T}\right.$, and $\mathrm{B}$ cells) were measured by flow cytometry, taken PBS treated group as $100 \%$.

\section{ELISA}

Solid phase ELISA was performed as previously described (Reitan and Hannestad, 2002), using 96-well polystyrene MaxiSorp microtiter plates (Nunc) which were coated with $10 \mu \mathrm{g} / \mathrm{mL}$ of purified P3 mAb and incubated with preimmune or hyperimmune sera dilute 1:100. Alkaline phosphatase-conjugated goat anti-mouse IgG (Fc $\gamma$-specific, Jackson Immunoresearch Laboratories) was used as second antibody. The reaction was developed with p-nitro-phenyl phosphate substrate (Sigma) in diethanolamine buffer ( $\mathrm{pH}$ 9.8). The absorbance was measured at $405 \mathrm{~nm}$ in an ELISA reader (Organon Teknika).

\section{FLOW CYTOMETRY}

Cells were obtained from inguinal lymph nodes and were incubated with PE-conjugated anti-mouse CD8a, FITC-conjugated anti-mouse CD4 and FITC-conjugated anti-mouse B220 (BD Pharmingen) for $30 \mathrm{~min}$ at $4^{\circ} \mathrm{C}$ and then washed with PBS twice. Cell surface antigen expression was evaluated by single- or doubleimmunofluorescence staining. Analysis was performed with a FACScan analyzer (Becton Dickinson, USA) and WinMDI 2.9 software.

\section{STATISTICAL ANALYSIS}

Differences in IgG antibody response against P3 mAb were evaluated by Mann-Whitney test. The comparison between the number of lymphocytes in the experimental groups treated in vivo with anti-CD8a antibody or cyclophosphamide were analyzed by Kruskal Wallis and Dunnett $t$-test. The differences in the percent of B16-F10 incidence was analyzed using Pearson's chi-square $\left(\chi^{2}\right)$ test. The differences were considered significant when $p \leq 0.05$. All statistical tests were one-tailed, and conducted using SSPS for Windows version 11.5.1 software.

\section{ACKNOWLEDGMENTS}

We thank to Yohan González from Experimental Immunotherapy Department for his work in animal care and manipulation.

Baskin, J. G., Ryan, T. M., Vakil, M., Kearney, J. F., and Lamon, E. W. (1990). Thymus-dependent antiidiotype and anti-antiidiotype responses to a dinitrophenyl-specific monoclonal antibody. J. Immunol. 145, 202-208.

Birkhofer, A., Rehbock, J., and Fricke, H. (1996). T lymphocytes from the normal human peritoneum contain high frequencies of Th2-type CD8+ T cells. Eur. J. Immunol. 26, 957-960.
Bogen, B., and Weiss, S. (1993). Processing and presentation of idiotypes to MHC-restricted T cells. Int. Rev. Immunol. 10, 337-355.

Cao, W., Tykodi, S. S., Esser, M. T., Braciale, V. L., and Braciale, T. J. (1995) Partial activation of CD8 + T cells by a self-derived peptide. Nature 378, 295-298.

Caux, C., Vanbervliet, B., Massacrier, C., Azuma, M., Okumura, K., Lanier, L. L., and Banchereau, J. (1994). 
B70/B7-2 is identical to CD86 and is the major functional ligand for CD28 expressed on human dendritic cells. J. Exp. Med. 180, 1841-1847.

Chapman, P. B., and Houghton, A. N. (1991). Induction of IgG antibodies against GD3 ganglioside in rabbits by an anti-idiotypic monoclonal antibody. J. Clin. Invest. 88, 186-192.

Cobbold, S. P., Jayasuriya, A., Nash, A., Prospero, T. D., and Waldmann, $\mathrm{H}$. (1984). Therapy with monoclonal antibodies by elimination of T-cell subsets in vivo. Nature 312, 548-551.

Cox, J. C., and Coulter, A. R. (1997). Adjuvants - a classification and review of their modes of action. Vaccine 15, 246-256.

Croft, M., Carter, L., Swain, S. L., and Dutton, R. W. (1994). Generation of polarized antigen-specific CD8 effector populations: reciprocal action of interleukin (IL)-4 and IL12 in promoting type 2 versus type 1 cytokine profiles. J. Exp. Med. 180, 1715-1728.

Cronin, D. C. II, Stack, R., and Fitch, F. W. (1995). IL-4-producing CD8+ T cell clones can provide B cell help. J. Immunol. 154, 3118-3127.

Diaz, A., Alfonso, M., Alonso, R., Saurez, G., Troche, M., Catala, M., Diaz, R. M., Perez, R., and Vazquez, A. M. (2003). Immune responses in breast cancer patients immunized with an anti-idiotype antibody mimicking NeuGc-containing gangliosides. Clin. Immunol. 107, 80-89.

Eyerman, M. C., and Wysocki, L. (1994). $\mathrm{T}$ cell recognition of somaticallygenerated $\mathrm{Ab}$ diversity. J. Immunol. 152, 1569-1577.

Eyerman, M. C., Zhang, X., and Wysocki, L. J. (1996). T cell recognition and tolerance of antibody diversity. J. Immunol. 157, 1037-1046.

Fynan, E. F., Webster, R. G., Fuller, D. H., Haynes, J. R., Santoro, J. C., and Robinson, H. L. (1993). DNA vaccines: protective immunizations by parenteral, mucosal, and gene-gun inoculations. Proc. Natl. Acad. Sci. U.S.A. 90, 11478-11482.

Hahn, B. H., Ebling, F., Singh, R. R., Singh, R. P., Karpouzas, G., and La Cava, A. (2005). Cellular and molecular mechanisms of regulation of autoantibody production in lupus. Ann. N. Y. Acad. Sci. 1051, 433-441.

Hermann, P., Van-Kooten, C., Gaillard, C., Banchereau, J., and Blanchard, D. (1995). CD40 ligand-positive CD8+ $\mathrm{T}$ cell clones allow $\mathrm{B}$ cell growth and differentiation. Eur. J. Immunol. 25, 2972-2977.

Hernandez, A. M., Toledo, D., Martinez, D., Grinan, T., Brito, V., Macias, A., Alfonso, S., Rondon, T., Suarez,
E., Vazquez, A. M., and Perez, R. (2008). Characterization of the antibody response against NeuGcGM3 ganglioside elicited in non-small cell lung cancer patients immunized with an anti-idiotype antibody. $J$. Immunol. 181, 6625-6634.

Ismaili, J., Brait, M., Leo, O., and Urbain, J. (1995). Assessment of a functional role of auto-anti-idiotypes in idiotype dominance. Eur. J. Immunol. 25 , 830-837.

Jacobsen, J., Erard, F., Wild, M. T., Garcia-Sanz, J. A., and Le Gros, G. (1993). Switch of CD8 T cells to noncytolytic CD8-CD4- cells that make TH2 cytokines and help B cells. Science 260, 1802-1805.

Jacobsen, J. T., Lunde, E., SundvoldGjerstad, V., Munthe, L. A., and Bogen, B. (2010). The cellular mechanism by which complementary Id+ and anti-Id antibodies communicate: T cells integrated into idiotypic regulation. Immunol. Cell Biol. 88, 515-522.

Lemoine, F. M., Cherai, M., Giverne, C., Dimitri, D., Rosenzwajg, M., Trebeden-Negre, H., Chaput, N., Barrou, B., Thioun, N., Gattegnio, B., Selles, F., Six, A., Azar, N., Lotz, J. P., Buzyn, A., Sibony, M., Delcourt, A., Boyer, O., Herson, S., Klatzmann, D., and Lacave, R. (2009). Massive expansion of regulatory $\mathrm{T}$-cells following interleukin 2 treatment during a phase I-II dendritic cell-based immunotherapy of metastatic renal cancer. Int. J. Oncol. 35, 569-581.

Lopez-Requena, A., De Acosta, C. M., Moreno, E., Gonzalez, M., Puchades, Y., Talavera, A., Vispo, N. S., Vazquez, A. M., and Perez, R. (2007a). Gangliosides, $\mathrm{Ab} 1$ and $\mathrm{Ab} 2$ antibodies I. Towards a molecular dissection of an idiotype-anti-idiotype system. Mol. Immunol. 44, 423-433.

Lopez-Requena, A., Rodriguez, M., De Acosta, C. M., Moreno, E., Puchades, Y., Gonzalez, M., Talavera, A., Valle, A., Hernandez, T., Vazquez, A. M., and Perez, R. (2007b). Gangliosides, $\mathrm{Ab} 1$ and $\mathrm{Ab} 2$ antibodies II. Light versus heavy chain: an idiotype-antiidiotype case study. Mol. Immunol. 44, 1015-1028.

Lu, F. X., Abel, K., Ma, Z., Rourke, T., Lu, D., Torten, J., Mcchesney, M., and Miller, C. J. (2002). The strength of $\mathrm{B}$ cell immunity in female rhesus macaques is controlled by CD8+ $T$ cells under the influence of ovarian steroid hormones. Clin. Exp. Immunol. 128, 10-20.

Mackall, C. L., Fry, T. J., and Gress, R. E. (2011). Harnessing the biology of IL-7 for therapeutic application. Nat. Rev. Immunol. 11, 330-342.
Maggi, E., Giudizi, M. G., Biagiotti, R., Annunziato, F., Manetti, R., Piccinni, M. P., Parronchi, P., Sampognaro, S., Giannarini, L., Zuccati, G., and Romagnani, S. (1994). Th2-like CD8+ T cells showing B cell helper function and reduced cytolytic activity in human immunodeficiency virus type 1 infection. $J$. Exp. Med. 180, 489-495.

Maruyama, H., Sperlagh, M., Zaloudik, J., Liang, S., Mizuki, K., Molthoff, C., and Herlyn, D. (2002). Immunization procedures for anti-idiotypic antibody induction in mice and rats. J. Immunol. Methods 264, 121-133.

Misharin, A. V., Rapoport, B., and Mclachlan, S. M. (2009). Thyroid antigens, not central tolerance, control responses to immunization in BALB/c versus C57BL/6 mice. Thyroid 19, 503-509.

Munthe, L. A., Kyte, J. A., and Bogen, B. (1999). Resting small B cells present endogenous immunoglobulin variable-region determinants to idiotope-specific CD4(+) T cells in vivo. Eur. J. Immunol. 29, 4043-4052.

Nakamura, Y., Watchmaker, P., Urban, J., Sheridan, B., Giermasz, A., Nishimura, F., Sasaki, K., Cumberland, R., Muthuswamy, R., Mailliard, R. B., Larregina, A. T., Falo, L. D. Gooding, W., Storkus, W. J., Okada, H., Hendricks, R. L., and Kalinski, P. (2007). Helper function of memory CD8+ T cells: heterologous CD8+ T cells support the induction of therapeutic cancer immunity. Cancer Res. 67, 10012-10018.

Nordoy, T., Husebekk, A., Aaberge, I. S., Jenum, P. A., Samdal, H. H., Flugsrud, L. B., Kristoffersen, A. C., Holte, H., Kvaloy, S., and Kolstad, A. (2001). Humoral immunity to viral and bacterial antigens in lymphoma patients 4-10 years after high-dose therapy with ABMT. Serological responses to revaccinations according to EBMT guidelines. Bone Marrow Transplant. 28, 681-687.

Parkman, R., Cohen, G., Carter, S. L., Weinberg, K. I., Masinsin, B., Guinan, E., Kurtzberg, J., Wagner, J. E., and Kernan, N. A. (2006). Successful immune reconstitution decreases leukemic relapse and improves survival in recipients of unrelated cord blood transplantation. Biol. Blood Marrow Transplant. 12, 919-927.

Perez, A., Lombardero, J., Mateo, C. Mustelier, G., Alfonso, M., Vazquez, A. M., and Perez, R. (2001). Immunogenetic analysis of variable regions encoding $\mathrm{AB} 1$ and gammatype AB2 antibodies from the NeuGc-containing ganglioside family. Hybridoma 20, 211-221.

Perez, A., Mier, E. S., Vispo, N. S., Vazquez, A. M., and Perez Rodriguez, R. (2002). A monoclonal antibody against NeuGc-containing gangliosides contains a regulatory idiotope involved in the interaction with $\mathrm{B}$ and T cells. Mol. Immunol. 39, 103-112.

Raz, E., Carson, D. A., Parker, S. E., Parr, T. B., Abai, A. M., Aichinger, G. Gromkowski, S. H., Singh, M., Lew, D., and Yankauckas, M. A. (1994). Intradermal gene immunization: the possible role of DNA uptake in the induction of cellular immunity to viruses. Proc. Natl. Acad. Sci. U.S.A. 91, 9519-9523.

Reitan, S. K., and Hannestad, K. (1995). A syngeneic idiotype is immunogenic when borne by IgM but tolerogenic when joined to IgG. Eur. J. Immunol. 25, 1601-1608.

Reitan, S. K., and Hannestad, K. (2001). The primary IgM antibody repertoire: a source of potent idiotype immunogens. Eur. J. Immunol. 31, 2143-2153.

Reitan, S. K., and Hannestad, K. (2002). Immunoglobulin heavy chain constant regions regulate immunity and tolerance to idiotypes of antibody variable regions. Proc. Natl. Acad. Sci. U.S.A. 99, 7588-7593.

Rodriguez, M., Roque-Navarro, L., Lopez-Requena, A., Moreno, E., Mateo De Acosta, C., Perez, R., and Maria Vazquez, A. (2007). Insights into the immunogenetic basis of two ganglioside-associated idiotypic networks. Immunobiology 212, 57-70.

Sad, S., Marcotte, R., and Mosmann, T. R. (1995). Cytokineinduced differentiation of precursor mouse CD8+ T cells into cytotoxic CD8+ $\mathrm{T}$ cells secreting Th1 or Th2 cytokines. Immunity 2, 271-279.

Saleh, M. N., Stapleton, J. D., Khazaeli, M. B., and Lobuglio, A. F. (1993). Generation of a human anti-idiotypic antibody that mimics the GD2 antigen. J. Immunol. 151, 3390-3398.

Salem, M. L., El-Naggar, S. A., Kadima, A., Gillanders, W. E., and Cole, D. J. (2006). The adjuvant effects of the toll-like receptor 3 ligand polyinosinic-cytidylic acid poly (I:C) on antigen-specific CD8+ T cell responses are partially dependent on NK cells with the induction of a beneficial cytokine milieu. Vaccine 24, 5119-5132. 
Salgame, P., Abrams, J. S., Clayberger, C., Goldstein, H., Convit, J., Modlin, R. L., and Bloom, B. R. (1991). Differing lymphokine profiles of functional subsets of human CD4 and CD8 T cell clones. Science 254, 279-282.

Sauer, K. A., Maxeiner, J. H., Karwot, R., Scholtes, P., Lehr, H. A., Birkenbach, M., Blumberg, R. S., and Finotto, S. (2008). Immunosurveillance of lung melanoma metastasis in EBI-3-deficient mice mediated by CD8+ T cells. J. Immunol. 181, 6148-6157.

Shanker, A., Verdeil, G., Buferne, M., Inderberg-Suso, E. M., Puthier, D., Joly, F., Nguyen, C., Leserman, L., Auphan-Anezin, N., and Schmitt-Verhulst, A. M. (2007). CD8 $T$ cell help for innate antitumor immunity. J. Immunol. 179, 6651-6662.

Stills, H. F. Jr. (2005). Adjuvants and antibody production: dispelling the myths associated with Freund's complete and other adjuvants. ILAR J. 46, 280-293.

Tseng, S. Y., Otsuji, M., Gorski, K., Huang, X., Slansky, J. E., Pai, S. I., Shalabi, A., Shin, T., Pardoll, D. M., and Tsuchiya, H. (2001). B7-DC, a new dendritic cell molecule with potent costimulatory properties for T cells. J. Exp. Med. 193, 839-846.

Vazquez, A. M., Alfonso, M., Lanne, B., Karlsson, K. A., Carr, A., Barroso, O., Fernandez, L. E., Rengifo, E., Lanio, M. E., Alvarez, C., Zeuthen, J., and Perez, R. (1995). Generation of a murine monoclonal antibody specific for $\mathrm{N}$ glycolylneuraminic acid-containing gangliosides that also recognizes sulfated glycolipids. Hybridoma 14, 551-556.

Vazquez, A. M., Perez, A., Hernandez, A. M., Macias, A., Alfonso, M., Bombino, G., and Perez, R. (1998). Syngeneic anti-idiotypic monoclonal antibodies to an anti-NeuGc-containing ganglioside monoclonal antibody. Hybridoma $17,527-534$.

Weiss, S., and Bogen, B. (1991). MHC class II-restricted presentation of intracellular antigen. Cell 64, 767-776.

Wysocki, L. J., Zhang, X., Smith, D. S., Snyder, C. M., and Bonorino, C. (1998). Somatic origin of T-cell epitopes within antibody variable regions: significance to monoclonal therapy and genesis of systemic autoimmune disease. Immunol. Rev. 162, 233-246.

Yu, P., Steel, J. C., Zhang, M., Morris, J. C., and Waldmann, T. A. (2010) Simultaneous blockade of multiple immune system inhibitory checkpoints enhances antitumor activity mediated by interleukin-15 in a murine metastatic colon carcinoma model. Clin. Cancer Res. 16, 6019-6028.

Zaghouani, H., Krystal, M., Kuzu, H., Moran, T., Shah, H., Kuzu, Y., Schulman, J., and Bona, C. (1992). Cells expressing an $\mathrm{H}$ chain Ig gene carrying a viral $\mathrm{T}$ cell epitope are lysed by specific cytolytic T cells. J. Immunol. 148, 3604-3609.

Zhang, X., Smith, D. S., Guth, A., and Wysocki, L. J. (2001). A receptor presentation hypothesis for $\mathrm{T}$ cell help that recruits autoreactive B cells. J. Immunol. 166, 1562-1571.

Zuluaga, A. F., Salazar, B. E., Rodriguez, C. A., Zapata, A. X., Agudelo, M. ands Vesga, O. (2006). Neutropenia induced in outbred mice by simplified low-dose cyclophosphamide regimen: characterization and applicability to diverse experimental models of infectious diseases. BMC Infect. Dis. 6, 55 . doi:10.1186/1471-2334-6-55

Conflict of Interest Statement: The authors declare that the research was conducted in the absence of any commercial or financial relationships that could be construed as a potential conflict of interest.

Received: 25 November 2011; accepted: 11 April 2012; published online: 26 April 2012.

Citation: Martínez D, Rodríguez $N$, Griñán T, Rondón T, Vázquez AM, Pérez R and Hernández AM (2012) P3 $m A b$ : an immunogenic anti-NeuGcGM3 antibody with unusual immunoregulatory properties. Front. Immun. 3:94. doi: 10.3389/fimmu.2012.00094

This article was submitted to Frontiers in $B$ Cell Biology, a specialty of Frontiers in Immunology.

Copyright $\odot 2012$ Martínez, Rodríguez, Griñán, Rondón, Vázquez, Pérez and Hernández. This is an open-access article distributed under the terms of the Creative Commons Attribution Non Commercial License, which permits noncommercial use, distribution, and reproduction in other forums, provided the original authors and source are credited. 


\section{APPENDIX}

A

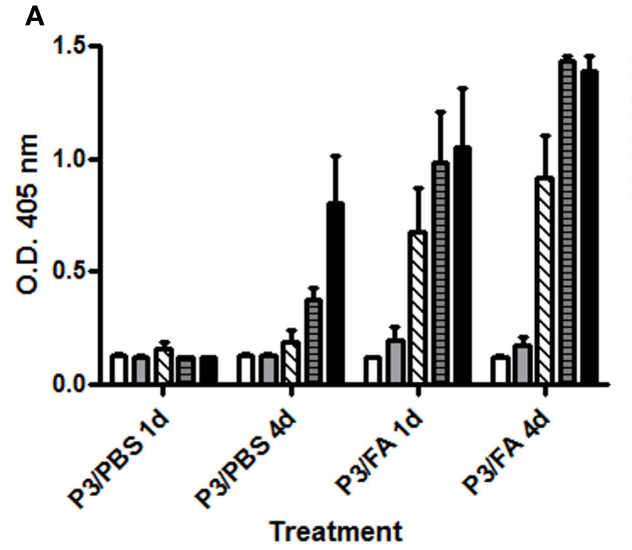

C

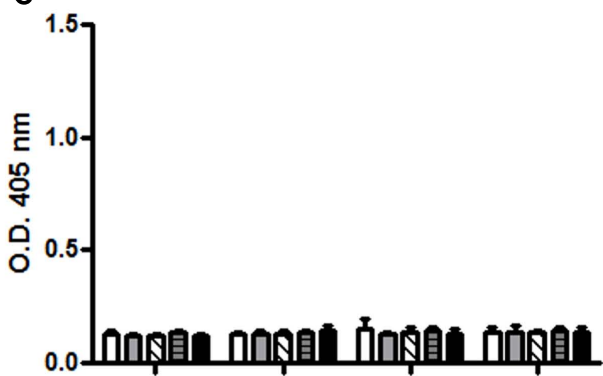

FIGURE A1 | Kinetic of IgG antibodies response in BALB/c mice. Mice were immunized with one (1d) or four (4d) doses of P3 mAb or an isotype control mAb in PBS or emulsified in Freund's adjuvant (FA).

Humoral response were tested against P3 $\mathrm{mAb}(\mathbf{A}, \mathbf{C})$ or isotype control mAb (B,D). The blood samples were obtained before the immunization
B

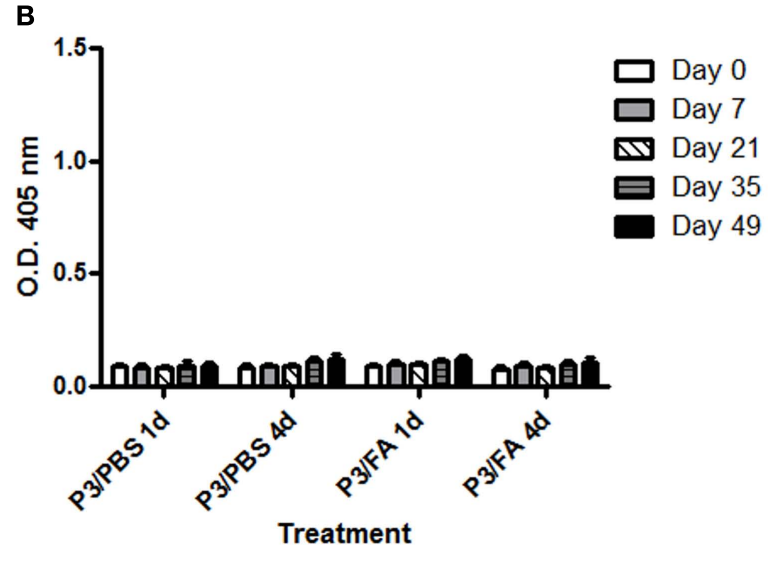

D

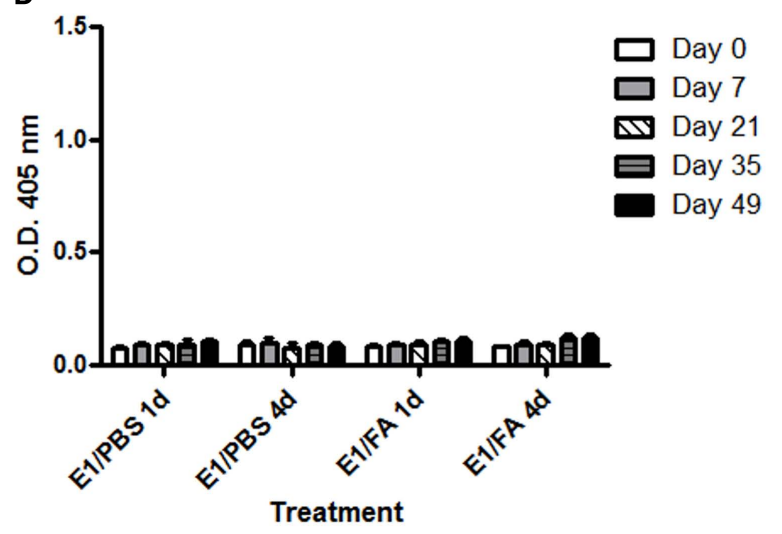

and on days $7,21,35$, and 49 of the immunization protocol. Sera were diluted 1:100 and the reactivity against purified P3 mAb was assessed by ELISA. Binding was determined using alkaline phosphatase-conjugated goat anti-mouse IgG (Fc $\gamma$-specific). Values are expressed as means $\pm S D$ $(n=5)$. 